\title{
Correction to: Optimal release time determination via fuzzy goal programming approach for SDE-based software reliability growth model
}

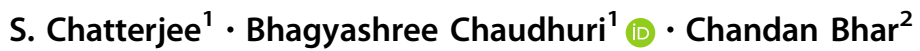

Published online: 20 November 2020

(C) Springer-Verlag GmbH Germany, part of Springer Nature 2020

\section{Correction to: Soft Computing}

https://doi.org/10.1007/s00500-020-05385-7

While typesetting the article, the affiliation for the corresponding author Bhagyashree Chaudhuri has been affiliation twice. The correct affiliation has been copied below.

Department of Mathematics and Computing, Indian Institute of Technology (ISM), Dhanbad, India.

The original article has been corrected.

Publisher's Note Springer Nature remains neutral with regard to jurisdictional claims in published maps and institutional affiliations.

The original article can be found online at https:// doi.org/10.1007/s00500-020-05385-7.

Bhagyashree Chaudhuri

chaudhuribhagyashree09@gmail.com

1 Department of Mathematics and Computing, Indian Institute of Technology (ISM), Dhanbad, Jharkhand, India

2 Department of Management Studies, Indian Institute of Technology (ISM), Dhanbad, Jharkhand, India 